\title{
eCOti
DiAno
}

Revista Mídia e Cotidiano

Artigo Seção Temática

Volume 13, Número 2, agosto de 2019

Submetido em: 26/07/2019

Aprovado em: 08/08/2019

\section{Michel Maffesoli e a pós-modernidade como fenômeno de comunicação}

\section{Michel Maffesoli and post-modernity as a phenomenon of communication}

\author{
Juremir Machado da SILVA ${ }^{1}$
}

\section{Resumo}

Neste artigo se examina a noção de pós-modernidade defendida pelo sociólogo francês Michel Maffesoli. Sustenta-se que para ele a pós-modernidade é a expressão de uma rede de comunicação em ato.

Palavras-chave: Michel Maffesoli; Pós-modernidade; Comunicação.

\begin{abstract}
This article examines the notion of postmodernity proposed by the French sociologist Michel Maffesoli. It argues that postmodernity represents the expression of a network of communication in action for the author.
\end{abstract}

Keywords: Michel Maffesoli; Postmodernity; Communication.

\section{Michel Maffesoli e sua obra}

Certos autores têm boas ideias, mas não perseveram na defesa das suas propostas. Parecem não acreditar no que eles mesmos perceberam em insights repentinos ou luminosos sobre fenômenos observados com maior ou menos atenção. Saltam de uma intuição - um insight é uma intuição formalizada como hipótese de trabalho - para outra sem convicção nem foco. Deixam para trás um rastro de pistas não exploradas ou mal examinadas e seguem em frente sem lamentações ou arrependimentos. Não é o caso do sociólogo francês Michel Maffesoli, que há décadas explora a noção de pós-modernidade como a melhor ferramenta possível para descrever o modo cotidiano de vida na passagem do século XX ao XXI.

\footnotetext{
${ }^{1}$ Doutor em Sociologia pela Université Paris V René Descartes. Professor titular da Pontifícia Universidade Católica do Rio Grande do Sul. E-mail: juremir@ pucrs.br
} 
As Humanidades, especialmente aquelas que se veem como Ciências Sociais Aplicadas, desprezam, cada vez mais, os ensaios, considerados como sendo destituídos de cientificidade e de respaldo empírico, e os livros, preteridos pelos periódicos científicos. Apesar disso, usam constantemente, como referencial teórico ou fonte de citações legitimadoras, livros de autores, entre os quais filósofos e teóricos de vários domínios, que não se amparam em pesquisas de campo nem publicam relatórios de investigação, contribuindo para o conhecimento com suas reflexões a partir de um pensamento elástico capaz de transformar visões panorâmicas em concentrados de interpretação do vivido. Cada área tem os seus valores e fetiches. A obsessão metodológica leva a que parte considerável dos trabalhos realizados não produza novos conhecimentos, resumindo-se a confirmar ou validar a metodologia adotada. Valem como testes de validade metodológica.

Michel Maffesoli observa o mundo vivido com uma lente cristalina e constantemente polida, como se ele fosse um artesão obsessivo. Cada livro é um retorno ao ponto de partida, tomando por foco um aspecto antes secundário. Para ele, os sinais da pós-modernidade estão por toda parte. Em um livro que sintetiza toda a obra que viria na sequência, A conquista do presente, publicado na França em 1979 e no Brasil em 1984, Maffesoli já explorava todos os temas que abrigaria depois sob a noção de pósmodernidade: o cotidiano como lugar do ordinário e do extraordinário, a relação social intensa, o jogo, o lúdico, o hedonismo, a diferença, o trágico como aceitação daquilo que é, a teatralidade das expressões sociais, o presenteísmo em oposição ao futurismo moderno, o valor das pequenas coisas que contam muito:

Não há dúvida de que o cinema apreende perfeitamente esse misto mágico. Os atos mais simples da vida cotidiana, os objetos mais triviais que constituem o meio circundante de todos os dias, as situações mais banais, tudo isso encontra, sob o olho da câmera, seus aspectos matizados e luxuriantes, fato importante que explica a fascinação que um filme exerce sobre o espectador. Contudo, essa cristalização cinematográfica nada mais faz do que acentuar um caráter encontrado na vida de todo dia. A vida 'humilde' e seus trabalhos simples só podem ser vividos na medida em que existe uma força mágica, poética que se alimenta sem cessar. A poética da vida cotidiana, as criações minúsculas e imperceptíveis permitem, de fato, a permanência da socialidade. Se não houvesse uma carga mágica na vida de todo dia, o 
aspecto mortífero da automatização venceria a pulsão do querer viver. A imagem estranha, fantástica, prospectiva, utópica, vale pelo que possui de banal. Reencontramos aqui a importância do duplo, onde a fascinação repousa no fato de que a imagem é sublimação, reflexo do empírico, do concreto (MAFFESOLI, 1979, p. 73).

Imagem é comunicação. Laço social. Se a modernidade sempre se orientou pela cadeia razão-progresso-emancipação (autonomia), a pós-modernidade, como expressão do cotidiano, é emoção-progressividade-relação. As ciências humanas não são demonstrativas, mas matérias de convencimento. $\mathrm{O}$ fato de alguém ser convencido por uma ideia pode ter consequências sobre a sua forma de viver. Nesse sentido, o mito da verdade irrefutável perde espaço para a força do consequencialismo. Maffesoli ocupa-se menos da prova do que da argumentação. Tenta mostrar e não demonstrar. Contenta-se em descrever, em apresentar os acontecimentos. Não quer prescrever. Talvez por isso seja visto por muitos como um ensaísta. E se for? Qual o problema? Como rejeitar ensaios que inseminam o mundo e irrigam modos de vida?

Hipótese: e se Michel Maffesoli for o mais perspicaz analista do seu tempo, aquele que melhor revela o que mobiliza as pessoas dando-lhes sentido, vontade de viver, disposição para continuar e prazer? Qual seria esse fator de mobilização capturado por ele? O desejo de pertencimento, a vontade de fazer parte de alguma coisa: de um clube, de uma tribo, de um grupo, de uma igreja, de um partido político, de uma religião, de uma seita, de uma equipe, de um agregado de pessoas com as quais se estabeleça laço social, contato, relação, fusão, vibração, ou seja, comunicação. E se Maffesoli estiver certo quanto ao aspecto central do modus vivendi atual: gregarismo de identificação em vez de individualismo extremado ou de identidades permanentes?

Em À sombra de Dionísio: contribuição a uma sociologia da orgia, publicado na França em 1982 e no Brasil em 1985, Maffesoli explicitou um elemento central da sua visão: a comunhão como uma comunicação de grau mais intenso:

A orgia, integração completa do contraditorial, não é necessariamente comunicação: é sobretudo comunhão. Aproximando-se assim do processo político ou pictórico, a 'arte da conjugação' favorece o êxtase coletivo, devolvendo aos diversos elementos que compõem a agregação sua pluralidade primitiva. A poesia transgride as normas da língua em sua expressão racional a fim de revelar imagens e sentimentos ocultos. 
Segundo Mallarmé, toda poesia pretende 'dar um sentido mais puro às palavras da tribo". O cuidado 'orgiástico' é idêntico. O contínuo estilhaçamento de si mesmo permite o surgimento de uma nova sintaxe coletiva. Exibindo à luz clara do dia a pluralidade negada pelo fantasma da unidimensionalidade ele retoma uma ordem complexa, mas orgânica - e geradora de toda socialidade (1985, p. 105).

A comunhão é uma forma intensa de comunicação. A fragmentação pósmoderna gera uma nova "sintaxe coletiva", do "eu" ao "nós", do separado ao que se multiplica e unifica na fusão, que é pluralidade em ato, da solidão ao compartilhamento. A orgia é metáfora da troca. Ao longo de toda uma obra consistente e encadeada, Maffesoli tem destacado as ideias que lhe parecem as mais cristalinas interpretações da vida como ela se dá a ver no cotidiano: desejo de compartilhamento (estar-junto, lógica tribal), hedonismo como busca do prazer intenso das festas regeneradoras, narcisismo como salutar cuidado de si, intensidade existencial como entrega ao aqui e agora, gosto por rituais como formas de atualização dos laços sociais, adesão a isto ou aquilo por identificações passageiras, efêmeras, mas intensas e sinceras, e não por identidades permanentes e engessadas, vibração.

Michel Maffesoli não tenta dizer como o mundo deve ser nem qual é a sua "essência”. Por que as pessoas gostam de vibrar juntas? Não há resposta. Há uma constatação. Elas gostam dessa relação intensa. Para o sociólogo do tribalismo pósmoderno, vale insistir, o importante é mostrar, não demonstrar, descrever, constatar, identificar aquilo que mobiliza as pessoas. $\mathrm{O}$ intelectual não deve se comportar como o guia iluminado que indica o caminho da emancipação, mas pode ser aquele que compreende as formas elementares de organização da vida social cotidiana. A atitude moderna por excelência era judicativa. A pós-moderna, compreensiva.

\section{A pós-modernidade e 0 "tesouro escondido"}

A primeira vez que Michel Maffesoli adota expressamente o termo pósmodernidade se dá no livro O tempo das tribos (1986, p. 137). 
Ce qui est certain c'est que la saturation d'une attitude projective, d'une intentionnalité tournée vers l'avenir, 'ex-tensive', est compensée par une augmentation de la qualité de relations qui sont plus 'in-tensives' et vécues au présent. La Modernité en multipliant la possibilité des relations sociales les avait pour partie vidées de tout contenu réel. Ce fut en particulier une caractéristique des métropoles modernes; et l'on sait que ce processus ne fut pas pour rien dans la grégaire solitude sur laquelle l'ont a tant glosé. La post-modernité, quant à elle, tend à favoriser dans les mégalopoles contemporaines à la fois le rétrécissement sur le groupe et un approfondissement des relations à l'intérieur de ces groupes.

Eis tudo. Saturação de uma postura voltada para o futuro, que prometia a emancipação e a felicidade num amanhã esplendoroso sempre adiado. Se a modernidade - projetiva, futurista, racional, progressista, explicativa, prometeica - jogava para frente a realização dos desejos e satisfação das expectativas, a pós-modernidade entrava em campo para dar novo conteúdo aos encontros sociais, favorecendo os pequenos grupos, apostando no presente, no imediato, no local, no vitalismo, na emoção, no compartilhamento, na troca, no lúdico, nas pequenas utopias, no possível, no provável, no praticável apesar dos obstáculos e dos jogos de poder. No lugar dos sacrifícios em nome de um futuro perfeito, a consumação dos desejos num presente imperfeito, mas real e ao alcance das mãos e das mentes.

Essa percepção da vida cotidiana como lastro da existência total jamais foi abandonada por Michel Maffesoli. Em 2019, quando do incêndio que destruiu parte da catedral Notre-Dame de Paris, em artigo para o suplemento cultural Caderno de Sábado, do jornal Correio do Povo, de Porto Alegre, o sociólogo das emoções compartilhadas encontrou traços da sua visão de mundo nas reações das multidões.

A emoção coletiva experimentada ao ver a catedral queimar nada mais é do que a persistência indestrutível daquilo que Joseph de Maistre chamou de "resíduo divino". Resíduo como um substrato sólido de qualquer sociedade, ou mesmo de qualquer cultura. Resíduo que, como a viga da piedade, está certamente enraizado num determinado lugar, mas não deixa de se irradiar de maneira ampla. Foi o suficiente para se ouvir, na multidão compacta, os murmúrios pronunciados em nossas línguas latinas, para entender a 'unidiversidade' da qual a Notre-Dame de Paris é o símbolo. Ela recolhe o que está espalhado. É o protótipo do 
enraizamento dinâmico, aquele da 'troca', em sentido amplo, que era pré-moderna e que certamente será pós-moderna² .

A mesma grade de interpretação pós-moderna, Michel Maffesoli, em parceria com Hélène Strohl, tem aplicado em relação às manifestações dos chamados "coletes amarelos", que protestam desde 2018 na França:

Estamos em uma crise, não primeiramente econômica ou social, mas numa verdadeira mudança de paradigma: a política é a gestão, a regulação da convivência, do viver juntos. É a ritualização da violência, a rivalidade homeopática, a regulação de várias paixões e emoções coletivas muitas vezes contraditórias. Essa política foi constituída na modernidade (século XVIII-XX) em democracia representativa: todos os corpos intermediários, todas as guildas, corporações e confrarias foram dissolvidas; os indivíduos se viram livres de quaisquer laços comunitários, ligados uns aos outros por um contrato social, um conjunto de normas que ditam o comportamento. Esses padrões são elaborados por seus representantes e se aplicam a todos. Isso não funciona mais: as pessoas não se sentem mais representáveis. Significa que se tornaram individualistas, que não têm senso do bem comum? De forma alguma. Ao contrário, significa que concebem o bem apenas como comum, isto é, registrado diariamente em sua comunidade de vida. É esse movimento de retorno, depois da modernidade, a uma 'socialidade' comunitária, de proximidade, implicando-me em um ser coletivo, pertencendo a várias tribos, que define o fim da modernidade ${ }^{3}$.

Um mundo apaga-se. Outro, floresce. Nada é totalmente sombrio ou exclusivamente luminoso. A pós-modernidade não sucede à modernidade numa linha evolutiva progressista, do pior para melhor, do menos desenvolvido para o mais desenvolvido, nem pode ser reduzida a um retrocesso, do mais racional para o menos racional. Moderno e pós-moderno convivem, coabitam, disputam espaço como sensibilidades antagônicas num espaço pluralista, paradoxal, instável e polissêmico.

Não se pode tomar pós-modernidade por um discurso positivo e incriticável em contraposição a uma modernidade negativa quanto ao presente e otimista quanto ao futuro, mas sempre passível de correções e reprimendas. Sob o guarda-chuva da pós-

\footnotetext{
2 “Caderno de Sábado”, Correio do Povo, 20 de abril de 2019, página central.

3 “Caderno de Sábado”, Correio do Povo, 15 de dezembro de 2018, p. 5.
} 


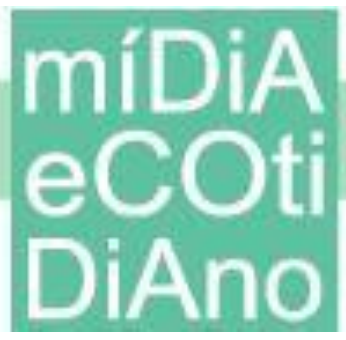

modernidade abrigam-se manifestações diversas e contraditórias. A ascensão da extremadireita em vários países do mundo ampara-se em muitos elementos que caracterizam o pós-moderno: retorno ao telúrico, valorização da proximidade, ênfase nas emoções, ritualizações, mitologias e símbolos. Em contrapartida, apesar dos discursos racionalizantes, as esquerdas também se mostram pós-modernas, sem o saber ou sem querer, quando valorizam o carisma do líder, as tendências partidárias como tribos, a política como espaço de vibração compartilhada, o transe coletivo:

Para além do paroxismo nazista, os 'estímulos semelhantes aos das brincadeiras de roda' multiplicaram-se na segunda metade do século XX. Não foi somente o rádio, como no caso de Hitler, a favorecer os transes coletivos, mas muitos outros 'novos meios'. Graças a estes, toda uma série de arcaísmos, em princípio superados, irrompeu na vida social. O rock, o jazz e outras músicas "bárbaras', o consumo frenético de objetos, as histerias esportivas, as grandes paradas políticas ou religiosas, tudo o que exprime, com estardalhaço, a nostalgia e o retorno da comunidade recebe ajuda do desenvolvimento tecnológico. Penso que aí se acha o ponto nodal da pós-modernidade: a sinergia do arcaísmo, essencialmente a nostalgia do 'nós', com a tecnologia. Diante dessa onda violenta que tudo arrasta ao passar, a independência, a personalidade e a crítica ao indivíduo não fazem mais sentido, mas cedem lugar à interdependência, ao mimetismo e à aceitação do que é (MAFFESOLI, 1997, p. 205).

Os “novos meios' de hoje são a internet e as redes sociais. As músicas "bárbaras" agora são o funk, o rap e a música eletrônica. O terror nazista encontra sucedâneo no terrorismo de ordem religiosa. $\mathrm{O}$ arcaico usa as tecnologias de ponta para disseminar ódio e mentiras, mas também a paixão e desejo de paz. A onda violenta que tudo arrasta, para bem ou para mal, revela uma vontade profunda de diluição no coletivo, nesse "nós" de fusão, um coletivo sem raiz fixa, sem necessária fixação. Os partidos políticos perdem credibilidade e mudam de nome para tentar aproximar-se do vivido. Querem chamar-se Cidadãos, Podemos, Rede, Novo, Solidariedade, Livres, Patriotas, Democratas. Qualquer designação que os arranque aparentemente da racionalidade moderna e os mergulhe nas identificações tribais pós-modernas.

Para Michel Maffesoli até mesmo a maçonaria, velha instituição de conspirações e causas diversas, ecoa esse desejo de estar-com, Em O tesouro escondido, 
carta aberta aos franco-maçons e a outros $(2019$, p. 22), para ele a maçonaria descarta o princípio formador por excelência da modernidade, a educação, e privilegia a iniciação; escolhe a associação fraternal ao princípio individualista; opta pela egrégora (energias espirituais coletivas) à lei do Pai; abraça a razão sensível em lugar do racionalismo; ampara-se na progressividade em vez de no culto do progresso linear; cultura a tradição e não a trajetória linear; fundamenta-se na irmanação e não no contrato social. Está, portanto, muito próxima do pacto emocional pós-moderno.

A maçonaria, para Maffesoli (2019, p. 145), é fraternidade, irmanação, “estarcom", convivência, vibração compartilhada, relação ritualmente atualizada, comunicação em estado permanente de comunhão:

Ora, são palavras que, utilizadas com discernimento, podem tornar-se palavras fundadoras. Muito precisamente na medida em que dizem, com justeza, o que é vivido. E, desse ponto de vista, é certo que a empatia volta a ser, sob vocábulos diferentes, um instrumento importante para compreender, em profundidade, os ajuntamentos contemporâneos: musicais, religiosos, políticos, esportivos, que pontuam a vida de nossas sociedades. Também, para compreender sua pertinência, talvez não seja inútil retornar a esta base maçônica que era o companheirismo para os maçons operativos, no qual se fundaram, a partir do século XVII, as diversas constituições que ordenam a abordagem iniciática. Em particular por isso que concerne à antiga e tradicional noção de 'irmandade', que se torna depois 'fraternidade', o que nomeio de 'irmanação' a fim de lhe restituir sua dimensão afetiva.

Seria possível e pertinente criticar Michel Maffesoli por afirmar que os intelectuais não podem ser judicativos nem devem dizer à sociedade o que ela deve ser, ao mesmo tempo que, ao fazer isso, julga os intelectuais e diz como eles devem ser? Ao privilegiar "o que é" sobre o "que deveria ser", Maffesoli transforma o "que é" no que “deve ser"? A resposta parece óbvia: as sociedades dizem o que querem ser e não podem ser desautorizadas. O conflito entre modernidade e pós-modernidade reside justamente nesse ruído comunicacional ou nesse mal-entendido compreensivo: a sociedade fala em emoção e forma comunidades de gozo, amparo mútuo e irmanação; intelectuais reprovam-na por ser pouco racional e demasiado individualista.

\section{Pós-modernidade como comunicação}


A pós-modernidade é um processo permanente de comunicação. Por meio da conjunção entre o arcaico - emoções e sentimentos - e a tecnologia de ponta (informática, internet), a comunicação pós-moderna, ou a pós-modernidade como comunicação, reverbera o espírito de um tempo, uma atmosfera, um estilo de vida, uma maneira de estar no mundo, um imaginário, entendendo-se por imaginário o fantástico do cotidiano, o extraordinário no ordinário, uma ficção subjetiva vivida como realidade objetiva, uma comunicação do inconsciente com a vida concreta.

As comunidades pós-modernas só se atualizam pela comunicação permanente. Não há laço social sem comunicação verbal ou não verbal. O vínculo é uma narrativa que se renova por meio de rituais formalizados ou não. A conversa cotidiana sobre futebol, por exemplo, ritualiza informalmente uma relação social orgânica através da qual um indivíduo se liga ao outro, formando comunidade, sem que haja uma institucionalização. A comunidade maçônica, por outro lado, formaliza seus rituais. Um partido político pressupõe uma organização por contrato social. Nesse sentido, encobre involuntariamente sua lógica ritualística comunicacional. Cada membro do partido, contudo, pode sentir-se ligado aos demais pelas ideias compartilhadas, pelas cores defendidas, pelas roupas vestidas, pelas bandeiras agitadas e pelas palavras de ordem gritadas, que são também palavras de identificação e servem de cimento tribal.

A questão da comunicação é explícita na obra de Maffesoli mesmo se não aparece em primeiro plano no palco dos temas que o preocupam e mudam de lugar a cada livro saindo do fundo da cena para assumir papel de protagonista. Em $O$ tesouro escondido (2019, p. 128), o assunto é enfocado com clareza de várias formas:

Ora, espírito há. E mesmo, cada vez mais, fora do racionalismo de que falamos. Isso que se encontra, à exaustão, na ebulição cultural e existencial que se desenvolve na horizontalidade da Internet. Onde o saber compartilhado, o "conhecimento ordinário", é bem o fato de um compartilhamento fraternal onde a palavra circula em uma comunicação sem fim. Comércio das ideias que traduz, fora dos caminhos batidos do conformismo, um inegável vitalismo que os velhos rabugentos de que falamos não podem suspeitar, a fortiori, apreciar.

A força vital do novo orgânico, aquele que atualiza arquétipos, vem do seu aspecto relacional. A relação é comunicação em ato. O que faz a sociedade se manter 


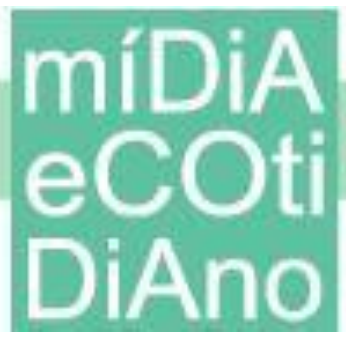

coesa é a sua capacidade de comunicação. É por meio desta que os vínculos sociais se renovam, reproduzem, atualizam e reforçam. Os "rabugentos" a que alude Maffesoli são aqueles que só pensam no conteúdo, na mensagem, no sentido. Questionam as redes sociais por nada dizerem de relevante. Não percebem que a relevância está no fato de que dizem coisas sem parar, não importando o quê. Essa comunicação vertiginosa cria laço social, junta, liga, cimenta, produz vibração e comunhão. O conteúdo é um pretexto para insistir nessa volúpia de comunicação e de vínculo.

É aí que a comunicação contemporânea entra em congruência com a ordem simbólica tradicional. Comunicação, termo bem gasto, mas que pode ser considerado como índice do desejo renovado de estar-com. A elevação do si individual ao Si holístico da comunidade. Esta busca do simbólico, que é preciso entender como conexão, reversibilidade, interação, alcança, então, a doutrina joanista da elevação de todos os homens, e mesmo de todas as coisas, a um nível superior (MAFFESOLI, 2019, p. 178).

Comunicar para sentir o corpo do outro, para estar em contato com o diferente ou com o igual, numa fusão quase mística, epifânica, embora cotidiana e recorrente. Elevação pelo banal, que se torna extraordinário pela mitologização do imaginário. Cada ato de comunicação se ampara no mais simples da vida, naquilo que a existência tem de mais autêntico e verdadeiro, a conversação de todo dia, feita de pequenas anedotas, de comentários sobre o que se vê na mídia, de provocações, brincadeiras, previsões, projeções, falas sobre doença, futebol, jogos, novelas, política, amores, o tempo, o clima, a violência, os temores, os sonhos, as esperanças, os filhos, a morte, disputas, paixões, promessas, dúvidas e tudo mais. Quando se fala por falar, na imensidão dos dias, faz-se dessa falação uma narrativa do vivido para o vivido.

Em 2009, Michel Maffesoli recebeu o título de Doutor Honoris Causa da Pontifícia Universidade Católica do Rio Grande do Sul por iniciativa do seu Programa de Pós-Graduação em Comunicação. Era o reconhecimento do seu papel como teórico das relações comunicacionais cotidianas em torno da mídia ou não. Em 2019, ele tornou-se Doutor Honoris Causa da Universidade La Salle, em Canoas, no Rio Grande do Sul. Mais uma, como o pensador que melhor entende e desvenda o imaginário da nossa época. $\mathrm{O}$ que ele continua a dizer? Que os seres humanos são mais comandados pelas emoções do 


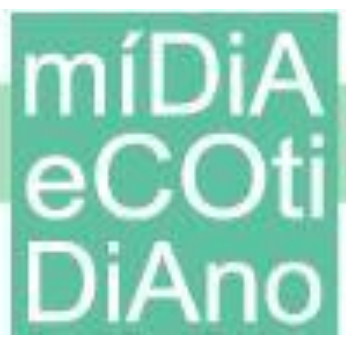

que pela razão. $\mathrm{O}$ fanatismo dos torcedores de futebol é uma prova disso que se mostra a cada dia com renovada intensidade. Adianta criticar? Não. A sociedade é o que é, não aquilo que intelectuais continuam a desejar que ela seja.

Como anda na contramão do racionalismo dominante, Maffesoli é, muitas vezes, atacado pelos pretensos donos do campo sociológico. Quer-se entender o que faz tanta gente participar de Centros de Tradição Gauchescas (CTGs) e de acampamentos farroupilhas (locais onde gaúchos reúnem a cada mês de setembro para comemorar o papel desempenhado por seus antepassados na guerra civil de 1835-1845 que opôs a província sulina ao Império? Leia-se Michel Maffesoli. Evidentemente que ele não diz uma palavra sobre isso. Dá o fundamento sociológico: lógica do estar-junto, do estarcom, do compartilhamento, cimento social, vontade de pertencer a alguma coisa forte, vibração compartilhada, tribalismo, identificação, troca emocional, ritualização de sentimentos, mitologização do cotidiano com ajuda do passado, produção e reprodução de laço social, vínculo orgânico, comunhão de linguagem, valores, estética, vocabulário, mitos, lendas, roupas, músicas, gestos, memórias.

Quer-se entender o que leva torcedores a viverem para um clube de futebol? Desejo de pertencimento a uma comunidade, prazer no êxtase compartilhado, satisfação na convivência tribal, aconchego na temperatura emocional da convivência, ainda que virtual, identificação, relacionamento. Quer-se compreender as relações estabelecidas no funk? A obra de Michel Maffesoli dá os instrumentos. Para Maffesoli, teórico dessa pósmodernidade definida como triunfo da materialidade sobre as projeções idealizadas, a utopia de um mundo totalmente racionalizado fracassou. Seres humanos produzem incessantemente mitos e imaginários. Buscam freneticamente a relação social que aquece e emociona. Escolhem mais emocionalmente do que pela razão por uma simples razão: a emoção é vetor de uma catarse que produz significação imediata. Os homens precisam do lúdico, do jogo e de rituais para encontrar sentidos que preencham o vazio deixado pelas promessas de redenção.

Sempre foi assim? Possivelmente. A diferença estaria no fato de que em muitos aspectos a identidade, cimento do futurismo ancorado no passadismo, foi substituída pela identificação, "cola" social do presente como medida de todas as sensações. As pessoas saltam de uma tribo para outra sem precisar dar explicações. Salvo, 


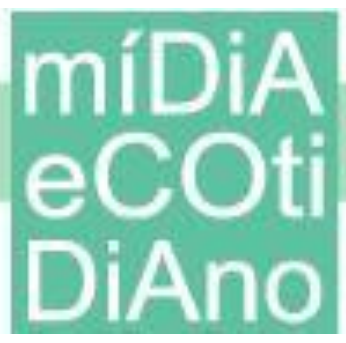

bem entendido, no futebol, onde a identidade moderna persevera como um vestígio arqueológico, resto de um tempo de fidelidades permanentes e invioláveis. Este é um tempo hiperindividualista e egoísta? Para Maffesoli, não. Segundo ele, mais uma vez, vive-se o tempo das tribos, passageiras ou nem tanto, em que se quer gozar intensamente aqui e agora, dentro do possível, do realizável, do desejável e do desejado. A modernidade prometia um futuro perfeito que se afastava como o horizonte. A massa fingia acreditar e tratava de aproveitar freneticamente o imediato.

Três coisas repetem-se ao longo da história na lógica maffesoliana: a necessidade de ocupar o tempo, o desejo de relação e compartilhamento de emoções, a necessidade de rituais de comunhão social. O homem não é da produção nem do consumo. Também é da produção e do consumo. Antes de tudo, como se tentou mostrar ao longo deste artigo, é do jogo, da festa, da crença, das emoções, dos mitos, dos desejos, das intuições, das religiões, das paixões e dos mistérios. Só o homem produz imaginários. Quando isso não funciona, o ser humano adoece, deprime-se, naufraga. O sentido para ele está no outro, esse outro que se alcança pelo compartilhamento de emoções, esse outro com o qual se cria laço social, esse outro com o qual se estabelece a troca que vincula, energiza, anima e põe em combustão.

Se uma narrativa mais poética não ofender a objetividade acadêmica, podese sugerir que o homem maffesoliano caminha dentro da noite como um fogo ardendo na solidão de um farol. Não sabe o que diz nem o que sente. Apenas aguarda a luz do dia para se lembrar do que foi quando queimava de vontade de viver e de mudar o mundo. Recorda-se dos amores esquecidos e dos compromissos com os assuntos úteis para a comunidade. Navega como um barco a deriva, padece feito uma catedral em ruínas, afunda os pés nos caminhos nunca mais cruzados, cantarola uma canção de ninar, repete para si uma ordem inclemente: hoje, como nunca, direi tudo o que sou, o que fui, o que serei. Quer agarrar a essência da existência como quem captura não o pássaro, mas o seu voo, a curva descrita na placidez azul de um céu de vilarejo. Esquece a concretude do mundo na sua obsessão pelas palavras, essas miragens feitas de sons e de imagens que nunca se deixam prender na gaiola de um texto, mas logo retoma o desejo de viver concretamente cada palavra. Sente pudor em largar tudo para encurralar lembranças. Sabe que não faz mais parte da confraria dos produtores, dos produtivos, dos construtores de 
realidade. Afaga o tecido da noite como quem estremece ao roçar de um veludo, talvez a recordação do gozo mais intenso, o gozo da vida como ela é, como ela se oferece para ser vivida, uma comunhão de sentidos.

A teoria não deixa de ser uma crônica sistematizada das ideias, tentativa desesperada de, como na poesia, "revelar imagens e sentimentos ocultos". No longínquo 1981, Maffesoli (1985, p. 177) advertia em tom de fechamento de livro:

\begin{abstract}
É preciso reconhecer que o porvir caótico que se anuncia não é muito tranquilizador para nossos espíritos habituados ao regime diurno do pensamento. Todavia, feitas todas as contas, a barbárie leniente da tecnoestrutura, em vias de estender-se ao mundo inteiro, nada tem de agradável e, tampouco, de divertido. Tanto mais que parece tratar-se, neste caso, de uma constante na história: as formas que se perfazem tendem a imobilizar-se em expressão totalitária. Então, mesmo que seja com temores e tremores, é melhor armar laços para a captura destes valores dionisíacos que (re)aparecem. Ninguém escapa ao destino. No máximo, podemos fazer como o anjo de Klee, que merece de $\mathrm{W}$. Benjamin o comentário de que "parece querer substrair-se a um espetáculo que o fascina”.
\end{abstract}

Talvez o que falte às ciências humanas não seja a tão falada objetividade científica, mas justamente a subjetividade que se abriga até na má poesia, mas que vive substancialmente em cada ato da vida banal das pessoas nos seus cotidianos.

Ser é estar-com.

\title{
Referências
}

MAFFESOLI, Michel. A conquista do presente. Rio de Janeiro: Rocco, 1984.

Graal, 1985.

À sombra de Dionísio: contribuição a uma sociologia da orgia. Rio de Janeiro: A transfiguração do político: a tribalização do mundo. Porto Alegre: Sulina, 1997.

Le temps des tribos: le déclin de l'individualisme dans les sociétés de masse. Paris: Paris, Méridiens Klincksieck, 1986.

O tesouro escondido: carta aberta aos franco-maçons e a outros. Porto Alegre: Sulina, 2019. 